\title{
High activity catechol 1,2-dioxygenase from Stenotrophomonas maltophilia strain KB2 as a useful tool in cis,cis-muconic acid production
}

\author{
Urszula Guzik • Katarzyna Hupert-Kocurek • \\ Małgorzata Sitnik - Danuta Wojcieszyńska
}

Received: 6 February 2013/Accepted: 22 March 2013/Published online: 28 March 2013

(C) The Author(s) 2013. This article is published with open access at Springerlink.com

\begin{abstract}
This is the first report of a catechol 1,2dioxygenase from Stenotrophomonas maltophilia strain KB2 with high activity against catechol and its methyl derivatives. This enzyme was maximally active at $\mathrm{pH} 8.0$ and $40{ }^{\circ} \mathrm{C}$ and the half-life of the enzyme at this temperature was $3 \mathrm{~h}$. Kinetic studies showed that the value of $K_{\mathrm{m}}$ and $V_{\max }$ was $12.8 \mu \mathrm{M}$ and $1,218.8 \mathrm{U} / \mathrm{mg}$ of protein, respectively. During our studies on kinetic properties of the catechol 1,2dioxygenase we observed substrate inhibition at $>80 \mu \mathrm{M}$. The nucleotide sequence of the gene encoding the $S$. maltophilia strain KB2 catechol 1,2dioxygenase has high identity with other catA genes from members of the genus Pseudomonas. The deduced 314-residue sequence of the enzyme corresponds to a protein of molecular mass $34.5 \mathrm{kDa}$. This enzyme was inhibited by competitive inhibitors (phenol derivatives) only by ca. $30 \%$. High tolerance against condition changes is desirable in industrial processes. Our data suggest that this enzyme could be of use as a tool in production of cis,cis-muconic acid and its derivatives.
\end{abstract}

U. Guzik $(\bowtie) \cdot$ K. Hupert-Kocurek .

M. Sitnik · D. Wojcieszyńska

Department of Biochemistry, Faculty of Biology and Environmental Protection, University of Silesia in Katowice, Jagiellonska 28, 40-032 Katowice, Poland e-mail: urszula.guzik@us.edu.pl
Keywords cis,cis-muconic acid production Stenotrophomonas - Catechol 1,2-dioxygenase . Substrate specificity $\cdot$ Kinetic

\section{Introduction}

Adipic acid is an important industrial compound, production of which is necessary for the manufacture of nylon, polyurethane, insecticides and bactericides. One of the most important intermediates during synthesis of this acid is cis,cis-muconic acid, which easily converts to adipic acid by hydrogenation (Wu et al. 2006). Moreover, cis,cis-muconic acid has reactive carboxylate groups and a configuration of conjugated double bonds that can be useful as a raw material for new functional resins, pharmaceuticals and agrochemicals (Bang et al. 1996; Wingard and Finn 1969). However, there have been no secure and economical methods to synthesize cis,cis-muconic acid. Several reports have described the preparation of this compound starting with straight-chain compounds, however, the product has been the more thermodynamically stable trans,trans isomer and therefore in recent years biological methods have been used more often to produce cis,cis-muconic acid (Wingard and Finn 1969). For example, Schmidt and Knackmuss (1984) described Pseudomonas sp. strain B13, which produced cis,cis-muconate and 
2-fluoro-cis,cis-muconate from benzoate and 3-fluorobenzoate. Kaneko et al. (2011) used recombinant Escherichia coli cells expressing the catA gene for highyield production of cis,cis-muconic acid from catechol. This gene codes for catechol 1,2-dioxygenase (1,2-CTD), which plays a key role in catalysing aromatic ring cleavage at the ortho position to yield cis,cis-muconic acid.

Recently several catechol 1,2-dioxygenases, generally from members of the genera Arthrobacter, Acinetobacter, Pseudomonas, Sphingomonas and Rhodococcus have been described (Earhart et al. 2005; Guo et al. 2009; Guzik et al. 2011; Kim et al. 1998; Matera et al. 2010; Matsumura et al. 2004; Melo et al. 2010; Murakami et al. 1998; Nadaf and Ghosh 2011; Saxena and Thakur 2005; Wang et al. 2006). Most of them are enzymes with molecular mass 30-34 kDa, which consist of two either identical or non-identical subunits (Bruijnincx et al. 2008; Bugg 2003; Guzik et al. 2011; Patel et al. 1976; Vaillancourt et al. 2006). At the dimeric interface is located a hydrophobic cavity which is connected to phospholipid molecules (Matera et al. 2010). Nonheme iron in the ferric state is used as a cofactor for intradiol dioxygenases (Bruijnincx et al. 2008; Bugg 2003; Guzik et al. 2011; Patel et al. 1976; Vaillancourt et al. 2006). The iron is ligated by two histidines and two tyrosines. The initial coordination geometry is trigonal bipyramidal with tyrosine, histidine and a bound hydroxyl in the equatorial plane, and the other tyrosine and histidine as axial ligands (Earhart et al. 2005). The catalytic cycle of the intradiol dioxygenases involves binding of the catechol as a dianion, binding of dioxygen to the metal, in sequence formation of a peroxo and hydroperoxo intermediate. In the next step, the Criegee rearrangement occurs and $\mathrm{O}-\mathrm{O}$ bond cleavage, which involves acyl migration to yield the cyclic anhydride and an iron-bound oxide or hydroxide, takes place. Hydrolysis of the anhydride leads to the formation of the final acyclic product (Bugg 2003; Bugg and Lin 2001; Vaillancourt et al. 2006; Vetting and Ohlendorf 2000).

Comprehensive studies on the substrate diversity and catalytic properties of catechol 1,2-dioxygenases are essential to facilitate the cheap and safe synthesis of cis,cis-muconic acid. Now we report novel a catechol 1,2-dioxygenase, characterized by high activity, isolated from Stenotrophomonas maltophilia strain KB2 which converted benzoic acid to cis,cismuconic acid. We have identified the gene encoding the catechol 1,2-dioxygenase in S. maltophilia KB2 and deduced a putative three-dimensional structure of this enzyme from the amino acid sequence.

\section{Materials and methods}

Media and culture conditions

Stenotrophomonas maltophilia KB2 (VTT E-113197) was cultivated in mineral salts medium (MSM), as described previously (Wojcieszyńska et al. 2011) in the presence of $6 \mathrm{mM}$ benzoic acid. Cultures were incubated at $30{ }^{\circ} \mathrm{C}$ and agitated at $130 \mathrm{rpm}$.

Preparation of cell extracts

Cells were harvested in the late exponential growth phase and centrifuged at $4,500 \times g$ for $15 \mathrm{~min}$ at $4{ }^{\circ} \mathrm{C}$. Next, the cells were washed with $50 \mathrm{mM}$ phosphate buffer, $\mathrm{pH}$ 7.0, and resuspended in the same buffer. Cells were sonicated $6 \times$ for $15 \mathrm{~s}$ and centrifuged at $9,000 \times g$ for $30 \mathrm{~min}$ at $4{ }^{\circ} \mathrm{C}$. The supernatant was used as crude extract for enzyme assays.

Enzyme assays

Benzoic acid was used as the inducer of catechol 1,2dioxygenase in the growth medium. Enzymatic activity of the enzyme was measured spectrophotometrically (Wojcieszyńska et al. 2011). After the addition of the enzyme, vials were incubated at $35^{\circ} \mathrm{C}$ in a water-bath with shaking. At specific time intervals, $1 \mathrm{ml}$ aliquots were withdrawn and used to monitor the reaction progress by measuring the product cis,cis-muconic acid at $260 \mathrm{~nm}$. The extinction coefficient of the oxidation product of catechol was determined as $\varepsilon_{260 \mathrm{~nm}}=16,800 / \mathrm{M} \mathrm{cm}$. One unit of enzyme activity was defined as the amount of enzyme required to generate $1 \mu \mathrm{mol}$ of product per minute at $35^{\circ} \mathrm{C}$. The protein concentration was determined by the dye-binding procedure of Bradford using bovine serum albumin as a standard (Bradford 1976).

$\mathrm{pH}$ and temperature optima of catechol 1,2-dioxygenase

The effect of $\mathrm{pH}$ on the enzyme activity was determined by measuring the activity at $35{ }^{\circ} \mathrm{C}$ over the $\mathrm{pH}$ range 2.2-12.0 using the following buffers: $0.05 \mathrm{M}$ 
glycine ( $\mathrm{pH} 2.2), 0.05 \mathrm{M}$ phosphate-citrate $(\mathrm{pH}$ 3.0-5.0), 0.05 M Sörensen ( $\mathrm{pH}$ 6.0-8.0), $0.05 \mathrm{M}$ borate $(\mathrm{pH}$ 9.0-10.0), and 0.05 Britton-Robinson (pH 11.00-12.00).

The optimum temperature was determined by assaying the enzyme activity at various temperatures $\left(4-60{ }^{\circ} \mathrm{C}\right)$ in $50 \mathrm{mM}$ phosphate buffer solution $(\mathrm{pH}$ $7.2)$.

Determination of kinetic constants of catechol 1,2-dioxygenase

The catalytic parameters (Michaelis-Menten constant, $K_{\mathrm{m}}$, and Maximum velocity, $V_{\max }$ ) for the enzyme were calculated by measuring the initial linear rates of the enzymatic reaction after the addition of different concentrations of catechol ranging from 0 to $100 \mu \mathrm{M}$ at $35{ }^{\circ} \mathrm{C}$. Three independent measurements were carried out for each substrate concentration. $K_{\mathrm{m}}$ and $V_{\max }$ were calculated from the Michaelis-Menten equation.

\section{Substrate specificity}

The impact of various substituted derivatives of aromatic compounds on enzyme activity was evaluated by incubating the enzyme with the respective aromatic compound (at $1 \mathrm{mM}$ ) for $3 \mathrm{~min}$ and assaying the activity. Dihydroxy-substituted derivatives of arene studied were 3- and 4-methylcatechol, 4,5- and 3,5-dichlorocatechol, and hydroquinone. The molar extinction coefficient used for the product from hydroquinone was $11,000 / \mathrm{M} \mathrm{cm}$ (at $320 \mathrm{~nm}$ ) (Kolvenbach et al. 2011; Spain and Gibson 1991). Catechol 1,2-dioxygenase activities for chlorinated and methylated derivatives of catechol were determined by the procedures of Dorn and Knackmuss (1978).

Activity in the presence of inhibitors

The impact of various phenols and chelators on enzyme activity was evaluated by incubating the enzyme with the respective inhibitor for $3 \mathrm{~min}$ and then assaying the residual activity. At specific time intervals, $1 \mathrm{ml}$ aliquots were withdrawn and used to monitor the reaction progress by measuring the product cis,cis-muconic acid. Assay of catechol 1,2dioxygenase was performed in the same way as in the case of non-inhibited enzyme. The phenols studied were 2-methylphenol, 3-methylphenol, 4-methylphenol, 2-chlorophenol, 4-chlorophenol, 2,4-dichlorophenol, each at $0.1,0.2$, and $0.3 \mathrm{mM}$ concentration. Chelators studied were phenanthroline, EDTA, and 2,2'-dipirydyl (each at 1, 2, and $3 \mathrm{mM}$ ).

Amplification of catechol 1,2-dioxygenase gene

Genomic DNA, plasmid DNA isolation and other DNA manipulations were carried out according to established procedures (Sambrook et al. 1989). Oligonucleotides for the PCR were purchased from IBB PAN (Warsaw, Poland). Detection of the 1,2-CTD gene was carried out with primer designed by Guzik et al. 2011 i.e. 1,2D_zewF (GATGGATCCGTGAAA ATTTCCCACATGC) and 1,2D_zewR (TGGATCCAGTAACGTTGCAGGTGCT). The PCR mixtures contained $0.5 \mu \mathrm{M}$ of each primer, $10 \times P f u$ buffer $+\mathrm{MgSO}_{4} \quad\left(2 \mathrm{mM} \mathrm{Mg}^{2+}\right), \quad 10 \mathrm{mM} \mathrm{K}^{+}, \quad 3 \%$ DMSO, $0.2 \mathrm{mM}$ of each deoxynucleoside triphosphate, $1.25 \mathrm{U} P f u$ DNA polymerase (Sigma) and plasmid or chromosomal DNA as a template. For the 1,2-CTD genes, the annealing temperature was $61{ }^{\circ} \mathrm{C}$ (30 s) in the first 10 cycles followed by a step down to $59{ }^{\circ} \mathrm{C}(30 \mathrm{~s})$ in the next 15 cycles, and $57{ }^{\circ} \mathrm{C}(30 \mathrm{~s})$ in the last 15 cycles. Aliquots $(10 \mu \mathrm{l})$ of the PCR products were analyzed by electrophoresis on a $1.0 \%$ agarose gel stained with $0.5 \mathrm{ug} / \mathrm{ml}$ ethidium bromide. Gene sequencing was performed by using a Big Dye ${ }^{R}$ Terminator Cycle Sequencing Kit (Applied Biosystem) and AbiPrism ${ }^{\circledR} 3100$ Genetic Analyzer. Computer analysis and processing of sequence information were performed by using Chromas LITE software (Technelysium Pty, Tewantin, Australia). The nucleotide sequence obtained for the catechol 1,2-dioxygenase gene from $S$. maltophilia strain KB2 has been deposited in the NCBI GenBank database under the accession number EU000397.1.

Molecular modeling of the catechol

1,2-dioxygenase enzyme

The amino acid sequence of the catechol 1,2-dioxygenase was deduced and followed by multiple sequence alignment using the CLC Free Workbench 6.3 software. The deduced structure of the catechol 1 , 2-dioxygenase was modeled using the interactive mode of the 3D-JIGSAW protein comparative modeling server (http://bmm.cancerresearchuk.org/ 3djigsaw/). 
Structure models as x.pdb data files were analyzed using RasMol 2.6 software package.

\section{Results and discussion}

Production of cis,cis-muconic acid by catechol 1,2-dioxygenase

In last few decades enzymes with potential for usage in chemical synthesis at the industrial scale have been sought. It is especially important for production of stereoisomers since enzymes exhibit regioselectivity and stereoselectivity (Ran et al. 2008). Several studies have demonstrated production of cis,cis-muconic acid by microorganisms from benzene, toluene, benzoic acid or catechol (Bang and Choi 1995; Bang et al. 1996; Frost and Draths 1996, 1997). For example, a mutant strain of Arthrobacter sp. produced $44 \mathrm{~g} / \mathrm{l}$ of cis,cismuconic acid in two days of culture (Mizuno and Yoshikawa 1990). For the further enhancement of the cis,cis-muconic acid productivity, it is necessary to obtain high activity catechol 1,2-dioxygenase, the key enzyme in the cis,cis-muconate biosynthetic pathway (Kim et al. 1998; Wu et al. 2006). An earlier study showed that catechol 1,2-dioxygenase from S. maltophilia KB2 was observed after growing the strain in the presence of benzoate (Wojcieszyńska et al. 2011). We considered that the formation of this compound is dependent on substrate concentration. Figure 1 shows that the rate of cis,cis-muconic acid synthesis averaged $10 \mu \mathrm{M} / \mathrm{min}$. The molar conversion yield based on the amount of consumed catechol was the theoretical value of $100 \%$ ( $\mathrm{mol} / \mathrm{mol})$. Similar results was obtained by Kaneko et al. (2011) during production of cis,cismuconic acid by recombinant $E$. coli cells that expressed a catA gene from Pseudomonas putida mt-2.

Sequence analysis of the catechol 1,2-dioxygenase gene

Genes encoding catechol dioxygenases can be located on plasmids or/and on the chromosome (Neidle et al. 1998; Sauret-Ignazi et al. 1996;Vaillancourt et al. 2006; Wojcieszyńska et al. 2011). Our research indicated that strain KB2 contains plasmid DNA (Wojcieszyńska et al. 2011) and we thus performed PCR with chromosomal and plasmid DNA as a template. To amplify the catechol 1,2-dioxygenase

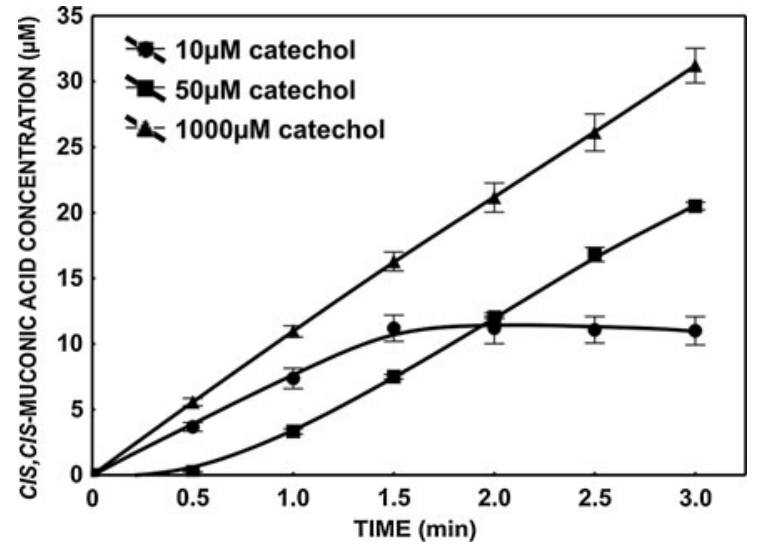

Fig. 1 Rate of cis,cis-muconic acid formation from various catechol concentrations (amount of used protein $7 \mu \mathrm{g}$ )

S. maltophilia KB2 gene we used primers 1,2D_zewF and 1,2D_zewR (Guzik et al. 2011). A PCR product was obtained only with chromosomal DNA as a template, indicating that the gene is located on the chromosomal DNA. Sequencing of the PCR product resulted in a 1243 nucleotide sequence (deposited in GenBank under accession number EU000397). A phylogenetic tree was created (Fig. 2), based upon the catechol 1,2-dioxygenase gene sequences found in GenBank and the new sequence obtained in this study. There was high homology found with other intradiol dioxygenase genes.

Structural properties of the catechol 1,2-dioxygenase

Knowledge of the catechol 1,2-dioxygenases 3-D structure can provide the important information into the molecular mechanisms of these enzymes. The deduced 314-residue amino acid sequence of $S$. maltophilia KB2 (deposited in the GenBank under accession number ABS86780.1) enzyme corresponds to a protein of molecular mass $34.5 \mathrm{kDa}$. Similar molecular weights for dioxygenase from Acinetobacter calcoaceticus and $P$. putida N6 were obtained by Neidle et al. (1998) and Guzik et al. (2011), respectively.

We predicted the 3-D structure of the catechol 1,2dioxygenase from strain KB2 based on the deduced amino acid sequence by using the interactive mode of the 3D-JIGSAW protein comparative modeling server. Catechol 1,2-dioxygenase from strain KB2 


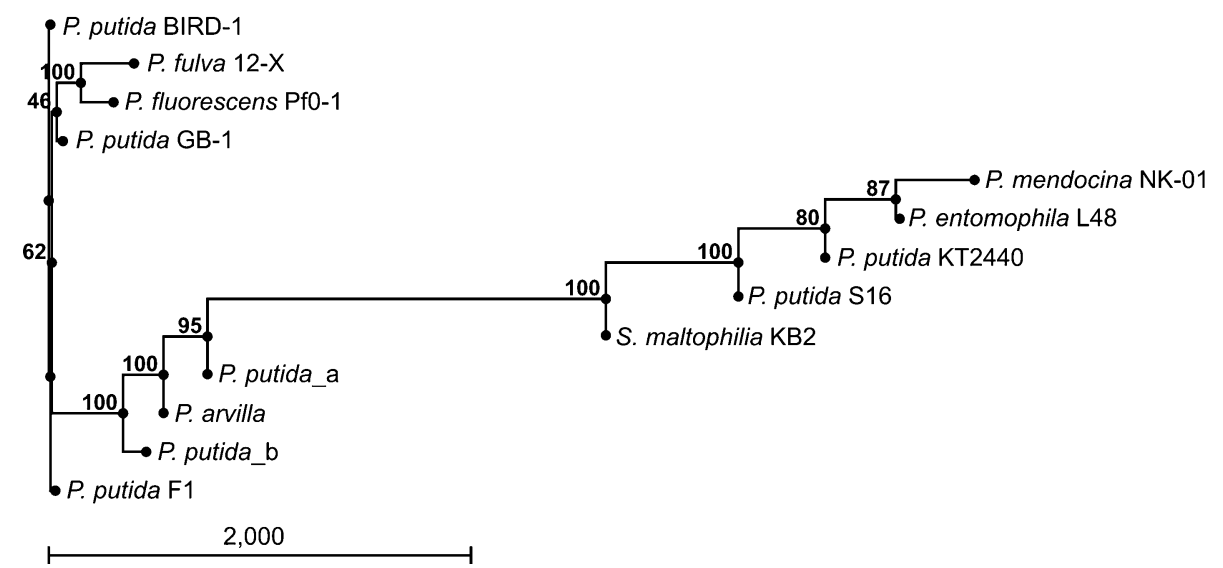

Fig. 2 Phylogenetic tree showing the position of the catechol 1,2-dioxygenase sequence from S. maltophilia KB2 in comparison with reference catechol 1,2-dioxygenases from other bacterial strains. The numbers at branch points indicate the confidence (in percent) as determined by bootstrap analysis with 100 replicates. The accession codes in the GenBank database and their origins are as follows: CP002290.1 for Pseudomonas putida BIRD-1 catechol 1,2-dioxygenase; CP002727.1 for Pseudomonas fulva 12-X catechol 1,2-dioxygenase; CP000094.2 for Pseudomonas fluorescens Pf0-1 catechol 1,2-dioxygenase; CP000926.1 for Pseudomonas putida GB-1 catechol 1,

(Fig. 3a) probably possesses an $N$-terminal domain with five $\alpha$ helices and a C-terminal domain consisting of $\beta$-sheets-structures typical for other intradiol dioxygenases as reported previously (Guzik et al. 2011; Ohlendorf et al. 1994; Vaillancourt et al. 1998). Similar molecular structure was also noted in another study of Pseudomonas arvilla C-1 catechol 1,2dioxygenase, catechol 1,2-dioxygenase and 4-chlorocatechol 1,2-dioxygenase from Rhodococcus opacus 1CP (Earhart et al. 2005; Ferraroni et al. 2004; Matera et al. 2010). The $\alpha$ helices localized within $N$-terminal domain of the enzyme of strain C-1, like other known intradiol enzymes, were found to be involved in dimerization of enzyme subunits (Bugg 2003; Vaillancourt et al. 2006; Wojcieszyńska et al. 2011).

Intradiol dioxygenases coordinate ferric ion by two histidine, two tyrosine residues and one hydroxyl ion in a trigonalbipyramidal geometry (Bruijnincx et al. 2008; Bugg and Lin 2001; Earhart et al. 2005; Ferraroni et al. 2004; Matera et al. 2010; Melo et al. 2010). Within the active site of the R. opacus 1CP 4-chlorocatechol 1,2-dioxygenase, the coordination residues were identified at positions His-194, His-196, Tyr-134, and Tyr-169 (Ferraroni et al. 2004). The catechol 1,2-dioxygenase isolated from this same 2-dioxygenase; CP002620.1 for Pseudomonas mendocina NK01 catechol 1,2-dioxygenase; CT573326.1 for Pseudomonas entomophila L48 catechol 1,2-dioxygenase; AE015451.1 for Pseudomonas putida KT2440 catechol 1,2-dioxygenase; EU000397 for Stenotrophomonas maltophilia KB2 catechol 1,2dioxygenase; D37782.1 for Pseudomonas putida_a catechol 1, 2-dioxygenase; D37783.1 for Pseudomonas arvilla catechol 1,2dioxygenase; AF363241.1 for Pseudomonas putida_b catechol 1,2-dioxygenase; CP000712.1 for Pseudomonas putida F1 catechol 1,2-dioxygenase

strain possess as iron ligands: Tyr-162, Tyr-196, His220, and His-222 (Matera et al. 2010). Our work predicts His-226 Tyr-166, and Tyr-200 to be involved in ferric ions coordination (Figs. 3b, c, 4). However, comparison of the deduced amino acid sequence of the catechol 1,2-dioxygenase from S. maltophilia KB2 with other catechol 1,2-dioxygenases has shown that one of conserved active-site residues was altered in the strain KB2 sequence. We predict Gln-224 as a fourth ligand of iron ion (Fig. 4). Displacing one of the key iron bound ligands can cause changes in catalytic properties of enzyme and therefore we examined these in our study.

Kinetic properties of catechol 1,2-dioxygenase in S. maltophilia KB2 cell extracts

The pH-activity and temperature-activity curves showed that the maximum catechol 1,2-dioxygenase activity $\left(3,062 \mathrm{U} / \mathrm{mg}\right.$ protein) was at $\mathrm{pH} 8$ and $40{ }^{\circ} \mathrm{C}$, respectively (Fig. 5a, b). On the other hand, the examined enzyme was not very stable in this temperature (Fig. 5c). The half-life of the enzyme at $40{ }^{\circ} \mathrm{C}$ was $3 \mathrm{~h}$ (Fig. 5b). Interestingly, the enzyme lost $16.5 \%$ of its enzymatic activity at $50{ }^{\circ} \mathrm{C}$ and the 

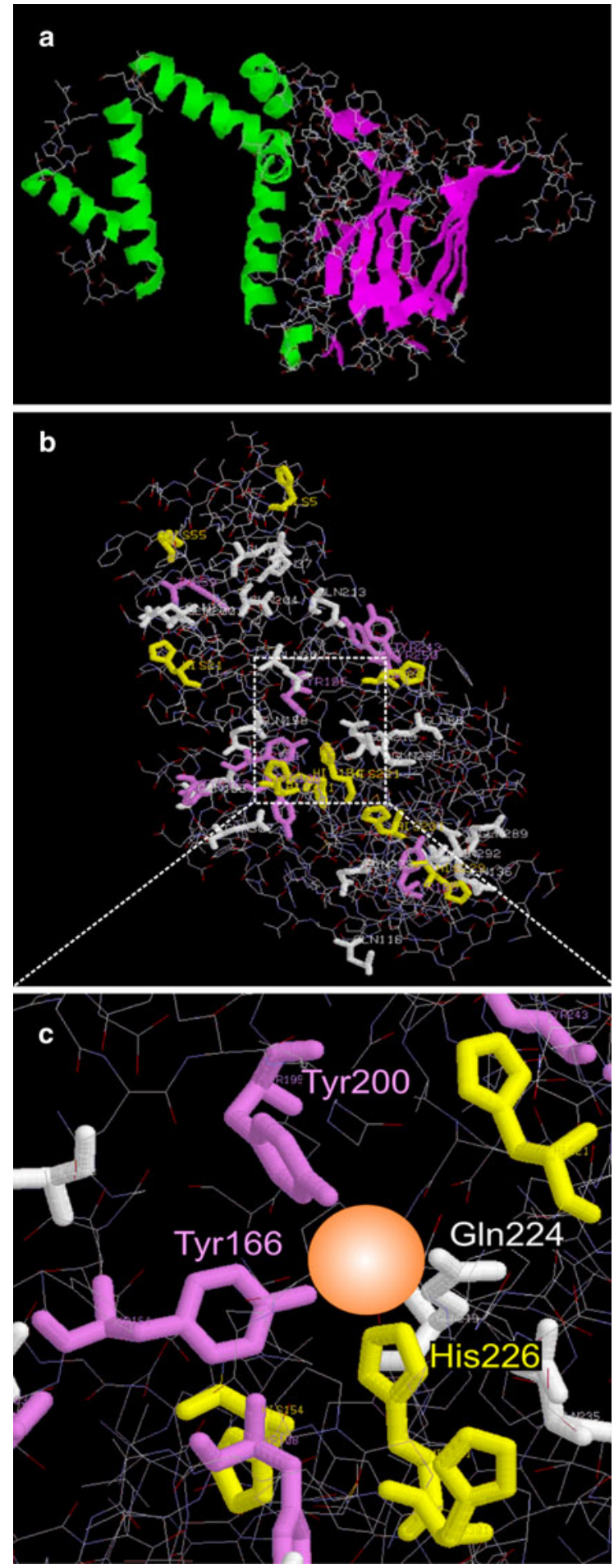

Fig. 3 The deduced 3-D structure of the catechol 1,2-dioxygenase from S. maltophilia KB2; a localization of the molecular domains; $\mathbf{b}$, and $\mathbf{c}$ amino acid residues involved in ferric ions coordination activity rapidly declined at $55^{\circ} \mathrm{C}$ (Fig. 5b). A similar effect was observed by Wang et al. (2006) and Murakami et al. (1998) for catechol 1,2-dioxygenase from Pseudomonas aeruginosa and Arthrobacter species BA-5-17, respectively. The enzyme isolated from strain KB2 lost $100 \%$ of its original enzymatic activity at $\mathrm{pH} 2.2$ and about $83 \%$ at $\mathrm{pH} 12.0$ (Fig. 5a). The optimal $\mathrm{pH}$ of the catechol 1,2-dioxygenase is high compared with that of catechol 1,2-dioxygenase from Pseudomonas fluorescens, P. aeruginosa and Rhodococcus sp. NCIM2891 (Nadaf and Ghosh 2011; Saxena and Thakur 2005; Wang et al. 2006).

In order to calculate values of $K_{\mathrm{m}}$ and $V_{\max }$ parameters, the activity of the $S$. maltophilia KB2 catechol 1,2-dioxygenase was measured at different substrate concentrations as detailed in Materials and Methods. The $K_{\mathrm{m}}$ and $V_{\max }$ values obtained were $12.18 \mu \mathrm{M}$ and $1,218.8 \mathrm{U} / \mathrm{mg}$ of protein, respectively (Fig. 5d). This $V_{\max }$ value is notably higher (approximately 20-100-fold) than the activity of other catechol 1,2-dioxygenases. Catechol 1,2-dioxygenase form Acinetobacter radioresistens showed $25.8 \mathrm{U} / \mathrm{mg}$ of protein (Briganti et al. 2000). Suvorova et al. (2006) and Solyanikova et al. (2009) characterized catechol 1,2-dioxygenase from $R$. opacus $1 \mathrm{CP}$ and $R$. opacus $6 \mathrm{a}$ with activities of $9.6 \mathrm{U} / \mathrm{mg}$ of protein and $55.5 \mathrm{U} / \mathrm{mg}$ of protein, respectively. Of note, the $K_{\mathrm{m}}$ value was 2-fold higher than those obtained by Wang et al. (2006) and Nadaf and Ghosh (2011). This result may therefore indicate lower affinity of enzyme to the substrate.

During our studies on kinetic properties of the catechol 1,2-dioxygenase, substrate inhibition at $>80 \mu \mathrm{M}$ was observed (Fig. 5d). In line with our results, Sauret-Ignazi et al. (1996) observed inhibition activity of an Alicaligenes eutrophus $\mathrm{CH} 34$ 1,2dioxygenase which catalyses tetrachlorocatechol degradation.

Influence of various substrates on catechol 1,2-dioxygenase activity in $S$. maltophilia $\mathrm{KB} 2$ cell extracts

Differences in substrate specificity is one of the interesting characteristics noted among the isofunctional dioxygenases from various sources. The relative activities of the catechol 1,2-dioxygenase from strain KB2 towards various substrates are given in Table 1 . It was found that the enzyme showed activity against 
Fig. 4 Multiple sequence alignment of predicted catechol 1,2-dioxygenase amino acid sequences carried out using CLC sequence viewer. Aligned sequences are 1,2-CTD of Acinetobacter calcoaceticus NCIB8250 (CAA85386.1), 1,2-CTD of Alcaligenes eutrophus $\mathrm{CH} 34$ (YP_587012.1), 1,2-CDT of Pseudomonas putida N6 (ABS86779.1), 1,2-CTD of Stenotrophomonas maltophilia $\mathrm{KB} 2$ (ABS86780.1), 1,2-CTD of Burkholderia sp. TH2 (BAC16779.1), CatA of Rhodococcus opacus 1CP (CAA67941.1), and 1,2CTD of Rhodococcus erythropolis AN-13 (BAA11859.1). Residues in solid boxes indicate the $\mathrm{Fe}$ ligands

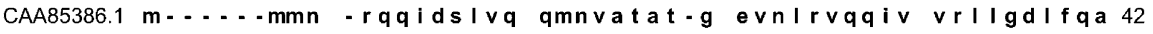

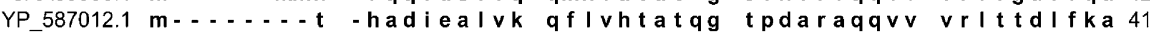

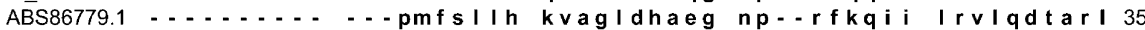
ABS 86780.1 l kdgsvkish - tadiqaffn qvagldhaeg kp--rfkqi i l rviqdtarl 47

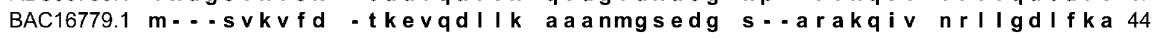

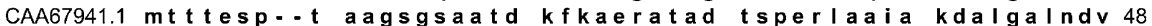
BAA11859.1 mtdidtavat ahasgnaatd kfktarvscd tsperaaij rdvisalgev 50

CAA85386.1 i ed Inmsqte I wkgley It d agqanelg I l aaglg I ehy I d I radeadak 92 YP_587012.1 i edId Isate vwkgieyfae agathelgI I aaglglerf I di radeaear 91 $A B S 86779.1$ ved I e itede fwhaidylnr lggrneagl I aaglgiehf I d I lqdakdae 85 ABS86780.1 i ed I e i tede fwhavdy In r lggrneagl I aaglgiehf I d I I qdakdae 97 BAC16779.1 idd Idmtpde iwagvhyfnk Igqdgeaa I l aaglg I ekf I di rmdaedka 94 CAA67941.1 i l khgvtype yrvfkqwIid vgeggewplf . . . Idvfi ehsveevlar 93 BAA11859.1 ihrhevtyde yrvIkqwmid vgeygewplw .... I d vf v ehqvedv-ny 94

CAA85386.1 agi t -ggt pr t i egplyvag apesvgfarm ddgsesahvd a I i iegnvtd 141 YP 587012.1 aglt $-\mathbf{g g t} \mathbf{p} \mathbf{t} \mathbf{i}$ egplyvag apestgfarl ddgteddkge vlfmqgtvyd 140 $A B S 86779.1$ aglg-ggt p r t i egplyvag aplaqgearm ddgtdp--gv vmf lqgqvfd 132 ABS86780.1 aglg-ggtpr t iegplyvag aplaqgevrm ddgtdp--gv vmf I qgqvfd 144 BAC16779.1 a $\mathbf{i} \mathbf{t}-\mathbf{g g t} \mathbf{p} \mathbf{r} \mathbf{i}$ egplyvag apvrdgiski dvnpdegagp - I virgtvtg 142 CAA67941.1 srkg-..t tmg siegpyyien spelpskct l pmreedekit plvfsgqvtd 140 BAA11859.1 srnglagt kg siegpyyvpd apqlpavctm pmreqdr r st plvfsgqvtd 144

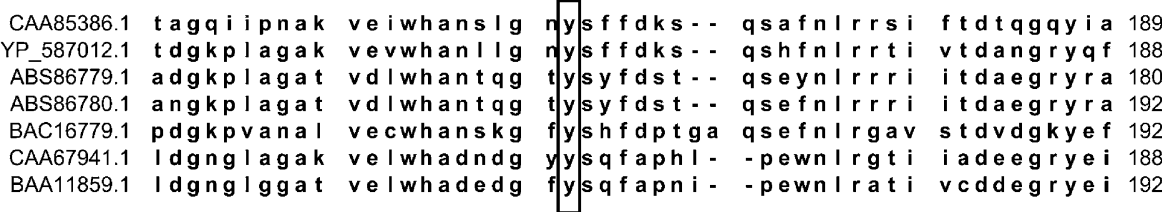
CAA85386.1 qt tmpvgygc ppegt tqa I I I Igrhgnrpshyhytusap gyrkIttqfn 239

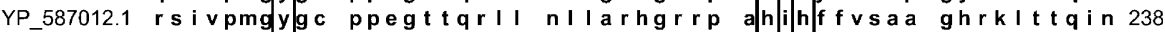
$A \bar{B} S 86779.1$ rsivpsgygc epagptqecl dilgrhgqrp ahylf fisap gfrhlttqin 230 ABS86780.1 rsivpsgygc epqsptqkcl nl lgrqgkap gavh fisap ghrhlttqin 242 BAC16779.1 rt Impvgygc pphgatqqI I nvIarhgnrp ahyhffvttd kyrkIttqin 242

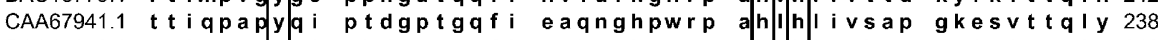

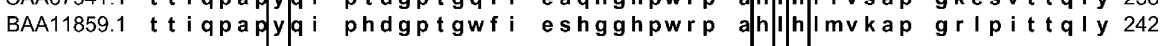

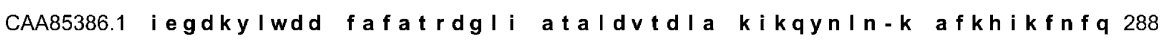
YP_587012.1 idgdey I wdd fafas rdglv pavervgdaa qldkhgvs-k pfas idfdf 287

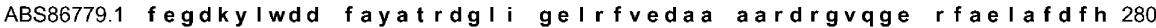
ABS86780.1 fagdkylwdd fayatrdgli gel rfvedaa aardrgvige rfaelsfdfr 292 BAC16779.1 iegdpliwdd fayatredli p-- - hvvekt ggtplgmkad tykeiefnie 289

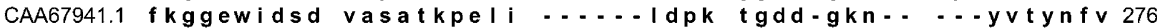
BAA11859.1 frggdwvetd vatavkpelv ..... Idpv rgad-gvn . . . rvaydfa 280

\begin{tabular}{|c|c|c|c|c|}
\hline CAA85386.1 & $I \vee q d a d q v p-$ & $-|q-\cdots r|$ & ivve & 305 \\
\hline YP 587012.1 & I I reatdapa & a evd $\cdots r$ I & $\mathrm{raa}$ & 307 \\
\hline ABS86779.1 & $I-q a a a$ a e & a e a rshrpra & I qeg & 302 \\
\hline ABS86780.1 & $I--q g a q s p d$ & a e ershrpra & I qeg & 314 \\
\hline BAC16779.1 & Itp I vhgkdn & $q I v s-r I r a$ & svt a & 311 \\
\hline CAA67941.1 & $I d p \ldots . .$. & $\ldots$ & $-\mathbf{a}$ & 280 \\
\hline BAA11859.1 & $I d p \ldots . .$. & $\ldots \ldots$ & $-t_{p}$ & 285 \\
\hline
\end{tabular}
\end{abstract}

catechol, 3-methylcatechol, and 4-methylcatechol. No activity was observed for 3-chloro- and 4-chlorocatechol, 3,5-dichloro- and 4,5-dichlorocatechol and hydroquinone. It could be interpreted that a haloatom might prevent the dioxygenase from attacking the ring. Similar results were obtained by Briganti et al. (2000), Matsumura et al. (2004) and Murakami et al. (1998) for intradiol dioxygenases isolated from $A$. radioresistens, Rhodococcus sp. AN-22 and Arthrobacter species BA-5-17, respectively. Giedraityte and Kalediene (2009) reported only 27 and $6 \%$ of the relative activity to catechol $(7.42 \mathrm{U} / \mathrm{mg}$ of protein) of a catechol 1,2-dioxygenase from Geobacillus sp. towards 3-methylcatechol and 4-methylcatechol, respectively. Remarkably broader substrate specificity was described by Wang et al. (2006) and Guo et al. (2009) during characterization of catechol 1,2-dioxygenases from $P$. aeruginosa and Sphingomonas xenophaga QYY, respectively. The catechol 1,2dioxygenase from $R$. opacus $1 \mathrm{CP}$ showed high activity against to catechol and methylcatechols. Moreover, this enzyme catalyzed cleavage of chlorocatechols, 

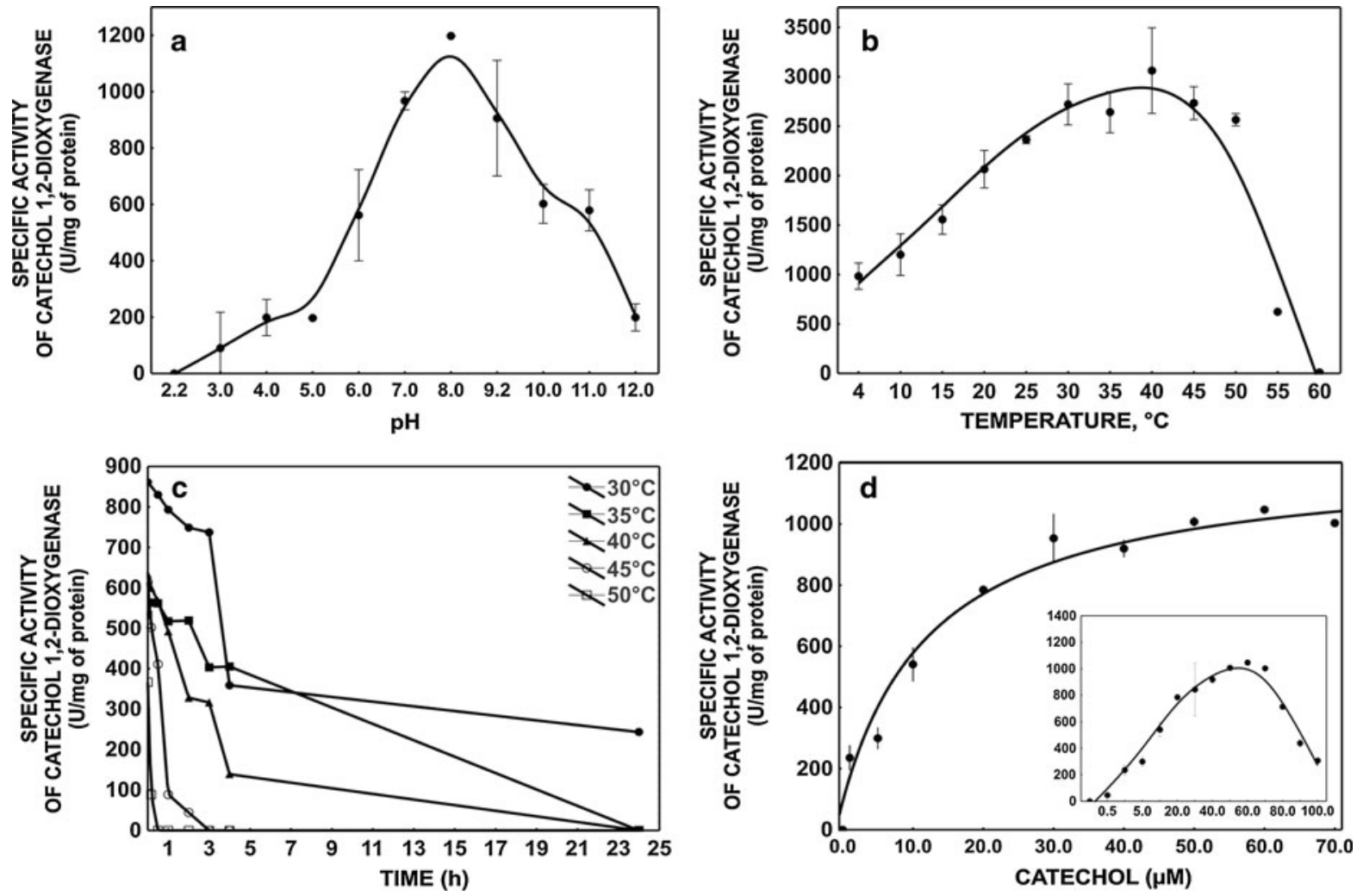

Fig. 5 Effects of $\mathrm{pH}(\mathbf{a})$, temperature (b), thermal stability (c) and substrate concentration (d) on catechol 1,2-dioxygenase activity in S. maltophilia KB2 cell extracts. The data points represent the average of 3 independent experiments

pyrogallol, hydroxyquinol, 2,3- and 3,4-dihydroxybenzoic acid ring (Matera et al. 2010).

Enzyme activity in S. maltophilia KB2 cell extracts in the presence of inhibitors

Phenols substituted in the ortho position, which structurally mimic catechols, are known as competitive inhibitors of catechol 1,2-dioxygenases because they coordinate to the iron (III) ion in the enzyme active site (Sauret-Ignazi et al. 1996; Vaillancourt et al. 1998). Most of the phenols studied affected enzyme activity at all tested concentrations (Table 2). Sauret-Ignazi et al. (1996) observed greater sensitivity of catechol 1,2-dioxygenase in the presence of para substituted phenols. However the catechol 1,2-dioxygenase from strain KB2 strain did not reveal dependence of activity changes on position and kind of substituents. A similar effect was observed by Kolomytseva et al. (2010) during analysis of the influence
Table 1 Substrate specificity of catechol 1,2-dioxygenase from $S$. maltophilia $\mathrm{KB} 2$

\begin{tabular}{lc}
\hline Substrate & Activity of free enzyme, \% \\
\hline Control-catechol & $100.0 \pm 0.0$ \\
3-Methylcatechol & $11.6 \pm 2.1$ \\
4-Methylcatechol & $23.0 \pm 0.6$ \\
3-Chlorocatechol & $0.0 \pm 0.0$ \\
4-Chlorocatechol & $0.0 \pm 0.0$ \\
3,5-Dichlorocatechol & $0.0 \pm 0.0$ \\
4,5-Dichlorocatechol & $0.0 \pm 0.0$ \\
Hydroquinone & $0.0 \pm 0.0$
\end{tabular}

Data shown represent the average of three independent trials \pm standard deviation

of monochloro- and monomethylphenols on activity of chlorocatechol 1,2-dioxygenases from Rhodococcus opacus $1 \mathrm{CP}$.

The sensitivity of the catechol 1,2-dioxygenase from strain $\mathrm{KB}$ to both ferrous and ferric iron chelators (Table 2) may reflect the fact that the iron of the 
Table 2 Effect of phenols and chelators on the activity of catechol 1,2-dioxygenase from $S$. maltophilia KB2

\begin{tabular}{|c|c|c|}
\hline Compound & $\begin{array}{l}\text { Concentration } \\
(\mathrm{mM})\end{array}$ & $\begin{array}{l}\text { Relative activity } \\
\text { of free enzyme }(\%)\end{array}$ \\
\hline None & & $100.0 \pm 0.0$ \\
\hline \multirow[t]{3}{*}{ 2-Methylphenol } & 0.1 & $75.3 \pm 6.9$ \\
\hline & 0.2 & $103.9 \pm 4.7$ \\
\hline & 0.3 & $82.4 \pm 5.4$ \\
\hline \multirow[t]{3}{*}{ 3-Methylphenol } & 0.1 & $79.6 \pm 4.3$ \\
\hline & 0.2 & $63.7 \pm 0.4$ \\
\hline & 0.3 & $68.3 \pm 2.4$ \\
\hline \multirow[t]{3}{*}{ 4-Methylphenol } & 0.1 & $92.1 \pm 6.5$ \\
\hline & 0.2 & $70.5 \pm 10.2$ \\
\hline & 0.3 & $72.5 \pm 0.4$ \\
\hline \multirow[t]{3}{*}{ 2-Chlorophenol } & 0.1 & $68.9 \pm 3.2$ \\
\hline & 0.2 & $67.3 \pm 0.8$ \\
\hline & 0.3 & $83.0 \pm 6.6$ \\
\hline \multirow[t]{3}{*}{ 4-Chlorophenol } & 0.1 & $89.0 \pm 6.8$ \\
\hline & 0.2 & $87.0 \pm 7.9$ \\
\hline & 0.3 & $87.0 \pm 5.0$ \\
\hline \multirow[t]{3}{*}{ 2,4-Dichlorophenol } & 0.1 & $74.0 \pm 3.4$ \\
\hline & 0.2 & $94.3 \pm 8.1$ \\
\hline & 0.3 & $70.2 \pm 2.6$ \\
\hline \multirow[t]{3}{*}{ Phenanthroline } & 1 & $1.0 \pm 0.0$ \\
\hline & 2 & $0.8 \pm 0.1$ \\
\hline & 3 & $0.0 \pm 0.0$ \\
\hline \multirow[t]{3}{*}{ EDTA } & 1 & $6.3 \pm 0.1$ \\
\hline & 2 & $5.7 \pm 0.3$ \\
\hline & 3 & $0.9 \pm 0.2$ \\
\hline \multirow[t]{3}{*}{ 2,2'-Dipirydyl } & 1 & $0.1 \pm 0.0$ \\
\hline & 2 & $0.0 \pm 0.0$ \\
\hline & 3 & $0.0 \pm 0.0$ \\
\hline
\end{tabular}

Data shown represent the average of three independent trials \pm standard deviation

enzyme active site is more weakly bound than in the enzyme from Arthrobacter species BA-5-17 (Murakami et al. 1998), Trichosporon cutaneum (Varga and Neujahr 1970), P. aeruginosa (Wang et al. 2006) A. calcoaceticus (Patel et al. 1976), or Rhodococcus sp. AN-22 (Matsumura et al. 2004). Varga and Neujahr (1970) suggested a correlation between substrate specificity and the affinity of iron to catechol 1,2-dioxygenases. They reported that dioxygenases with strongly bound iron had narrow substrate specificity and vice versa. Our results are at variance with this suggestions since the catechol 1,2-dioxygenase from strain KB2 has a narrow specificity and apparently weakly bound iron. The sensitivity of our enzyme ton the chelators may be connected with the untypical ligand (Gln-224) of iron in the active site of the dioxygenase (Fig. 3c).

In conclusion catechol 1,2-dioxygenase from S. maltophilia strain KB2 could be a useful tool in the production of cis,cis-muconic acid and its derivatives due to its high activity. The high activity of the enzyme in the presence of methylcatechols may enables it to be used to produce methyl derivatives of cis,cis-muconic acid. Moreover, the temperature and $\mathrm{pH}$ tolerance, and resistance to competitive inhibitors, may be desirable features of the catechol 1,2-dioxygenase from KB2 strain for industrial processes .

Acknowledgments We thank Dr Renata Zub (Department of Molecular Biology, Institute of Oncology, Warsaw, Poland) for DNA sequencing. Aleksandra Bury is acknowledged for her excellent technical assistance.

Open Access This article is distributed under the terms of the Creative Commons Attribution License which permits any use, distribution, and reproduction in any medium, provided the original author(s) and the source are credited.

\section{References}

Bang SG, Choi CY (1995) DO-stat fed-batch production of cis,cis-muconic acid from benzoic acid by Pseudomonas putida BM014. J Ferment Bioeng 79:381-383

Bang SG, Choi WJ, Choi CY, Cho MH (1996) Production of cis,cis-muconic acid from benzoic acid via microbial transformation. Biotechnol Bioprocess Eng 1:36-40

Bradford MM (1976) A rapid and sensitive method of the quantitation of microgram quantities of protein utilizing the principle of protein-dye binding. Anal Biochem 72:248-258

Briganti F, Pessione E, Giunta C, Mazzoli R, Scozzafava A (2000) Purification and catalytic properties of two catechol 1,2-dioxygenase isozymes from benzoate-grown cells of Acinetobacter radioresistens. J Protein Chem 19:709-716

Bruijnincx PCA, van Koten G, Gebbink RJMK (2008) Mononuclear non-heme iron enzymes with the 2-His-1-carboxylate facial triad: recent development in enzymology and modeling studies. Chem Soc Rev 37:2716-2744

Bugg TDH (2003) Dioxygenase enzymes: catalytic mechanisms and chemical models. Tetrahedron 59:7075-7101

Bugg TDH, Lin G (2001) Solving the riddle of the intradiol and extradiol catechol dioxygenases: how do enzymes control hydroperoxide rearrangements? Chem Commun 35:941-952

Dorn E, Knackmuss MJ (1978) Chemical structure and biodegradability of halogenated aromatic compounds-substituent effects on 1,2-dioxygenation of catechol. Biochem J 174:85-94 
Earhart CA, Vetting MW, Gosu R, Michaud-Soret I, Que L, Ohlendorf DH (2005) Structure of catechol 1,2-dioxygenase from Pseudomonas arvilla. Biochem Biophys Res Commun 338:198-205

Ferraroni M, Solyanikova IP, Kolomytseva MP, Scozzafava A, Golovleva L, Briganti F (2004) Crystal structure of 4-chlorocatechol 1,2-dioxygenase from chlorophenol-utilizing Gram-positive Rhodococcus opacus 1CP. J Biol Chem 279:27646-27655

Frost JW, Draths KM (1996) Synthesis of adipic acid from biomass-derived carbon sources. United States Patent No. $5,487,987$

Frost JW, Draths KM (1997) Bacterial cell transformants for production of cis,cis-muconic acid and catechol. United States Patent No. 5,616,496

Giedraityte G, Kalediene L (2009) Catechol 1,2-dioxygenase from $\alpha$-naphthol degrading thermophilic Geobacillus sp. strain: purification and properties. Cent Eur J Biol 4:68-73

Guo M, Qu YY, Zhou JT, Li A, Uddin MS (2009) Characterization of catechol 1,2-dioxygenase from cell extracts of Sphingomonas xenophaga QYY. Sci China Ser B-Chem 52:615-620

Guzik U, Greń I, Hupert-Kocurek K, Wojcieszyńska D (2011) Catechol 1,2-dioxygenase from the new aromatic compounds-degrading Pseudomonas putida strain N6. Int Biodeter Biodegr 65:504-512

Kaneko A, Ishii Y, Kirimura K (2011) High-yield production of cis,cis-muconic acid from catechol in aqueous solution by biocatalyst. Chem Lett 40:381-383

Kim BJ, Choi WJ, Lee EY, Choi CY (1998) Enhancement of cis,cis-muconate productivity by overexpression of catechol 1,2-dioxygenase in Pseudomonas putida BCM114. Biotechnol Bioprocess Eng 3:112-114

Kolomytseva MP, Ferraroni M, Chernykh AM, Scozzafava A, Briganti F, Golovleva LA (2010) Experimental and theoretical affinity of substituted phenols to chlorocatechol 1,2dioxygenases: a step toward the comprehension of inhibitor/substrate binding to intradiol dioxygenases. J Mol Catal B-Enzyme 64:53-59

Kolvenbach BA, Lenz M, Bendorf D, Rapp E, Fousek J, Vlcek C, Schaffer A, Gabriel FLP, Kohler H-PE, Corvini PFX (2011) Purification and characterization of hydroquinone dioxygenase from Sphingomonas sp. strain TTNP3. AMB Express 1:1-8

Matera I, Ferraroni M, Kolomytseva M, Golovleva L, Scozzafava A, Briganti F (2010) Catechol 1,2-dioxygenase from the gram-positive Rhodococcus opacus 1CP: quantitative structure/activity relationship and the crystal structures of native enzyme and catechol adducts. J Struct Biol 170:564-584

Matsumura E, Ooi S, Murakami S, Takenaka S, Aoki K (2004) Constitutive synthesis, purification, and characterization of catechol 1,2-dioxygenase from the aniline-assimilating bacterium Rhodococcus sp. AN-22. J Biosci Bioeng 98:71-76

Melo FA, Araujo APU, Costa-Filho AJ (2010) Role of cis,cismuconic acid in the catalysis of Pseudomonas putida chlorocatechol 1,2-dioxygenase. Int J Biol Macromol 47:233-237

Mizuno S, Yoshikawa N (1990) Microbial production of cis,cismuconic acid. J Biotechnol 14:203-210
Murakami S, Wang CL, Naito A, Shinke R, Aoki K (1998) Purification and characterization of four catechol 1,2dioxygenase isozymes from the benzamide-assimilating bacterium Arthrobacter species BA-5-17. Microbiol Res 153:163-171

Nadaf NH, Ghosh JS (2011) Purification and characterization of catechol 1,2-dioxygenase from Rhodocococcus sp. NCIM 2891. Res J Environ Earth Sci 3:608-613

Neidle EL, Hartnett Ch, Bonitz S, Ornston LN (1998) DNA sequence of the Acinetobacter calcoaceticus catechol 1,2dioxygenase I structural gene catA: evidence for evolutionary divergence of intradiol dioxygenases by acquisition of DNA sequence repetitions. J Bacteriol 170:48744880

Ohlendorf DH, Orville AM, Lipscomb JD (1994) Structure of protocatechuate 3,4-dioxygenase from Pseudomonas aeruginosa at $2.15 \AA$ resolution. J Mol Biol 244:586-608

Patel RN, Hou CT, Felix A, Lillard MO (1976) Catechol 1,2dioxygenase from Acinetobacter calcoaceticus: purification and properties. J Bacteriol 127:536-544

Ran N, Zhao L, Chen Z, Tao J (2008) Recent applications of biocatalysis in developing green chemistry for chemical synthesis at the industrial scale. Green Chem 10:361372

Sambrook J, Fritsch EF, Maniatis T (1989) Molecular cloning: a laboratory manual, 2nd edn. Cold Spring Harbor Laboratory Press, New York

Sauret-Ignazi G, Gagnon J, Béguin J, Barrelle M, Markowicz Y, Pelmont J, Toussaint A (1996) Characterisation of chromosomally encoded catechol 1,2-dioxygenase (E.C. 1.13.11.1) from Alcaligenes eutrophus $\mathrm{CH} 34$. Arch Microbiol 166:42-50

Saxena P, Thakur S (2005) Purification and characterization of catechol 1,2-dioxygenase of Pseudomonas fluorescens for degradation of chlorobenzoic acid. Indian $\mathrm{J}$ Biotechnol 4:134-138

Schmidt E, Knackmuss H-J (1984) Production of cis, cis-muconate from benzoate and fluoro-cis,cis-muconate from 3-fluorobenzoate by benzoate degrading bacteria. Appl Microbiol Biotechnol 20:351-355

Solyanikova IP, Konovalova EI, Golovleva LA (2009) Methylcatechol 1,2-dioxygenase of Rhodococcus opacus 6 a is a new type of the catechol-cleaving enzyme. Biochemistry (Moscow) 74:994-1001

Spain JC, Gibson DT (1991) Pathway for biodegradation of $p$ nitrophenol in a Moraxella sp. Appl Environ Microbiol 57:812-819

Suvorova MM, Solyanikova IP, Golovleva LA (2006) Specificity of catechol ortho-cleavage during para-toluate degradation by Rhodococcus opacus 1CP. Biochemistry (Moscow) 71:1316-1323

Vaillancourt FH, Han S, Fortin PD, Bolin JT, Eltis LD (1998) Molecular basis for the stabilization and inhibition of 2,3dihydroxybiphenyl 1,2-dioxygenase by t-butanol. J Biol Chem 273:34887-34895

Vaillancourt FH, Bolin JT, Eltis LD (2006) The ins and outs of ring-cleaving dioxygenases. Crit Rev Biochem Mol Biol 41:241-267

Varga JM, Neujahr HY (1970) Purification and properties of catechol 1,2-oxygenase from Trichosporon cutaneum. Eur J Biochem 12:427-434 
Vetting MW, Ohlendorf DH (2000) The $1.8 \AA$ crystal structure of catechol 1,2-dioxygenase reveals a novel hydrophobic helical zipper as a subunit linker. Structure 8:429-440

Wang C-L, You S-L, Wang S-L (2006) Purification and characterization of a novel catechol 1,2-dioxygenase from Pseudomonas aeruginosa with benzoic acid as a carbon source. Process Biochem 41:1594-1601

Wingard LB, Finn RK (1969) Oxidation of catechol to cis,cismuconic acid with ozone. I\&EC Product Res Dev 8:65-70
Wojcieszyńska D, Guzik U, Greń I, Perkosz M, Hupert-Kocurek $\mathrm{K}$ (2011) Induction of aromatic ring-cleavage dioxygenases in Stenotrophomonas maltophilia strain KB2 in cometabolic systems. World J Microbiol Biotechnol 27:805-811

Wu C-M, Wu C-CSuC-C, Lee S-N, Lee Y-A, Wu J-Y (2006) Micriobial synthesis of $c$ is, cis-muconic acid from benzoate by Sphingobacterium sp. mutants. Biochem Eng J 29:35-40 